\title{
AOR
}

Selected Papers of \#AoIR2020: The $21^{\text {st }}$ Annual Conference of the

Association of Internet Researchers Virtual Event / 27-31 October 2020

\section{'LURKER' LITERACIES: LIVING IN/THROUGH NEIGHBORHOOD FACEBOOK GROUPS}

\author{
Gina Sipley \\ SUNY Nassau Community College/ Hofstra University \\ Understanding 'lurker' literacies
}

Although mythologized as a fringe or deviant behavior, 'lurking,' or passive participation in an online group, has become a regular part of the way we lead our lives online. In a discussion with Jenkins and Ito (2016), danah boyd questions the current emphasis on active online participation. She posits two salient questions: "Can someone be a valuable and participatory lurker?" and "What does high quality listening look like?"(Jenkins, Itō, \& boyd, 2016, p.112). From a literacy studies perspective, "high quality listening" is a metaphor for reading, and reading is a highly active process. In Facebook groups, an optional feature for people to virtually gather around a common interest, where membership can be measured in the thousands, it is far more common to 'lurk', then it is to respond in words, shares, likes, memes, or emoji to content we have read.

To 'lurk' or engage in these so-called passive online reading practices is not neutral. Just as no act of reading or writing can ever be neutral (Street, 1993). A reader's relationship with the verbal symbols on the page is an "experiential reservoir" of personal, social, historical, and political influences (Rosenblatt, 1969). This relationship between text and reader is not fixed, but continually shifting and evolving. Rosenblatt's work pre-dates the rise of social networking technologies and the study of digital literacies; however, this does not mean that her work is not relevant to the study of Facebook groups. New technologies mean new ways of reading, writing, and communicating and these technologies proliferate as a response to society's increasing desire to engage. As Street (1993) explains, a literacy practice is more than an observable behavior it is the way language is used in everyday life; it involves values, attitudes, feelings, and social relationships. The popular practice of 'lurking' in a neighborhood Facebook group affects personal and professional relationships among people living in the same geographic community, even if these effects cannot be Suggested Citation (APA): Sipley, G. (2020, October). 'Lurker' Literacies: Living In/Through Facebook Neighborhood Groups. Paper presented at AoIR 2020: The 21 th Annual Conference of the Association of Internet Researchers. Virtual Event: AolR. Retrieved from http://spir.aoir.org. 
visually captured using vanity metrics, a term used to describe the quantifiable capture of likes, shares, and comments, that algortihmically ascribe value to a post.

Despite the popularity of Facebook groups, they are just beginning to be studied by scholars and 'lurkers' have not yet been the site of a socio-cultural or transactional literacy study. The Facebook group feature is particularly worthy of investigation because extensive analyses performed prior to the U.S. midterm elections found that it is Facebook's groups "that represent the greatest short-term threat to election news and information integrity"(Albright, 2018). My IRB approved dissertation research, which will be completed by the end of October 2020, examines 'lurking' in NYC suburban neighborhood Facebook groups during the COVID-19 pandemic. Through a qualitative study of Facebook users enrolled in the same neighborhood Facebook groups, this study seeks to describe both the 'lurker' literacy practices of Facebook group users and to understand if and how the features of the Facebook social media platform encourage these literacy practices. Given that neighborhood groups are intended for people who are in the same geographic area, many members of the group know one another offline and in real life. This adds an additional layer of connectivity worthy of analysis. Since 'lurkers' are groups that are typically not included in academic studies, this research will have broad appeal to scholars across the social sciences. When scholars only examine the role of active contributors and ignore the literacy practices of the silent majority of 'lurkers', their findings present an incomplete portrait of the way people engage in participatory culture and how these online experiences influence our lives offline.

\section{Methodology}

This two-part qualitative study used community mapping of self-reported literacy practices and extensive interviews of Facebook users in New York City suburban neighborhood Facebook groups to describe the literacy practices involved in 'lurking' and to describe the Facebook features, policies, and transactions that may encourage 'lurker' literacies. The study addresses the questions: 1) In what ways do so-called Facebook 'lurkers' engage in literacy practices?; 2) What makes these individuals choose to engage in these literacy practices on Facebook?; 3) In the minds of these Facebook users, what role might Facebook, itself, as a social media platform, play in their decision to 'lurk' and in the creation of 'lurker' literacies?; 4) From the participants' perspective, what other factors might influence their choices about how publicly to engage in literacy practices within Facebook?

The study began with a general query to the 15 neighborhood Facebook groups, spanning three local areas of varying socioeconomic circumstances, of which I am already a member. The total number of people I am connected to across all 15 groups is 102,793 . Community mapping invited these 102,793 Facebook group members to use Padlet to anonymously list and tally the literacy practices they engage in while 'lurking' (defined in the study as reading, but not commenting, liking, or sharing Facebook group content). Since 'lurking' is a context specific behavior that all users engage in, responses from any Facebook user are valuable. A preliminary list of these 'lurker' literacy practices included: researching; saving posts for future annotation and curation outside of the Facebook platform; attending local events; having a face-to-face conversation with someone about group content; supporting local businesses; using an 
alternate social media platform to post about content learned via a Facebook group; taking political action.

I then shared a post to each of the 15 Facebook groups inviting members who participated in the community mapping to contact me for follow up interviews and thus far I have conducted interviews with 16 people. Utilizing the AoIR guidelines for ethical research, participants reflected on reasons why they chose to engage in these literacy practices and in what contexts.

\section{Findings}

The interview data continues to be collected, coded, and analyzed with NVivo software at the time of this publication. Preliminary findings from social mapping indicate that individuals engage in a wide range of literacy practices, including: receptive reading to better understand divergent opinions; low-commitment entertainment in-between daily activities; engaging in face-to-face and text message conversation about private group content; supporting local businesses; taking screenshots; and researching and curating information. Interviews revealed that participants choose to engage in these so-called passive practices because they want to understand oppositional opinions, but also minimize the risk of professional or economic consequences for expressing an unpopular opinion and resist arguing with their neighbors. Individuals shift from passive to active participation, such as commenting on a thread, if they feel they have an expertise in a particular area, if they know the original poster in real life, or if they genuinely believe that what they post will be helpful to the group. Facebook features that encourage this kind of participation include limited implementation of the seen feature; save function; follow thread; use of real names and avatars; friends of friends limits; algorithmic frequency in newsfeed.

\section{References}

Albright, J. (2018, November 16). The Shadow Organizing of Facebook Groups - The Micro-Propaganda Machine - Medium. Retrieved from https://medium.com/s/the-micropropaganda-machine/the-2018-facebook-midterms-part-ii-shadow-organizationc97de1c54c65

Jenkins, H., Itō, M., \& boyd, d. (2016). Participatory culture in a networked era: A conversation on youth, learning, commerce, and politics. Cambridge, UK: Polity Press.

Rosenblatt, L. M. (1969). Towards a Transactional Theory of Reading. Journal of Reading Behavior, 1(1), 31-49. https://doi.org/10.1080/10862969609546838

Street, B. (1993). Introduction: The new literacy studies. In B. Street (Ed.), Crosscultural approaches to literacy (pp. 1-21). New York, NY: Cambridge University Press. 